\title{
Interinext.
}

\section{El sector automotriz en méxico y Brasil: Un análisis desde la perspectiva comercial}

\author{
Yolanda Carbajal-Suárez ${ }^{1}$ e María Esther Morales-Fajardo \\ Facultad de Economía, Universidad Autónoma del Estado de México, Ciudad de México, México
}

\section{DETALHES DO ARTIGO}

\section{Histórico do artigo:}

Recebido em 15 de março de 2016

Aceito em 27 de setembro de 2016

Disponível online em 31 de dezembro de 2016

Sistema de Revisão "Double Blind Review"

Editor científico

Ilan Avrichir

\section{Palavras-chaves:}

Sector automotriz; México; Brasil; ACE 55; Intercambio comercial

\author{
RESUMO
}

\begin{abstract}
Se analizó el desempeño y características del sector automotriz en México y Brasil, con énfasis en los diferentes senderos tomados por las respectivas industrias y el intercambio bilateral. El análisis determinó que Brasil ha dado prioridad al fortalecimiento de su mercado interno, mientras que México claramente ha dado prioridad al mercado de exportación. A nivel bilateral, la importancia del intercambio comercial radica en el comercio del sector industrial, particularmente del sector automotriz; sin embargo, esta relación se ha visto disminuida a raíz del diferendo ocurrido en el marco del Acuerdo de Complementación Económica (ACE) 55.
\end{abstract}

(C) 2016 Internext | ESPM. Todos os direitos reservados!

\section{Introducción}

Brasil y México cuentan con una industria automotriz que impacta en el crecimiento económico y que es espacio de vinculación comercial bilateral. El sector automotriz durante el siglo XXI se convirtió en el punto de encuentro entre las dos economías al detonar, primero, un aumento en las balanzas comerciales; y a inicios del 2012 un diferendo entres las dos naciones.

La importancia del sector automotriz en estos países es evidente: en 2015, México se consolidó como el séptimo productor de vehículos en el mundo con una producción total de 3,565,469 unidades, ocupó la quinta posición como productor y exportador de autopartes, (AMIA, 2016). En lo que concierne al empleo, contaba con 745,197 empleos directos, 77,642 en la elaboración de autos y camiones y 667,555 en la de autopartes. Su contribución al Producto Interno Bruto (PIB) total fue de $3.0 \%$ y $17.7 \%$ al manufacturero (INEGI, 2015 y 2016).

\footnotetext{
${ }^{1}$ Author's contact: Email: ycarbajals@uaemex.mx
}

Brasil, no obstante, ha presentado un estancamiento en el sector de manera reciente, es el noveno productor a nivel mundial con 2,429,421 unidades manufacturadas en 2015. En 2013 está industria generó más de 1.5 millones de empleos directos e indirectos. En ese mismo año contribuyó con $21 \%$ del PIB industrial y $5 \%$ del PIB total. En Brasil están presentes 29 empresas ensambladoras, 494 empresas fabricantes de autopartes y 61 unidades industriales distribuidas en 10 estados (ANFAVEA, 2014).

Dentro de la literatura especializada sobre las relaciones comerciales de los países se encuentra Siqueiros (2007), quien analiza el régimen de controversias en el marco del ACE No. 55, entre México y el Mercosur. El autor considera que el protocolo adicional pactado con Brasil dirime las diferencias entre ambas economías, pero delimita su solución sobre los parámetros multilaterales de la Organización Mundial de Comercio (OMC) o por un grupo ad hoc. Rosas (2008) por su parte estudia las relaciones bilaterales históricas de rivalidad 
fundamentadas en la lejanía geográfica, la interposición de Estados Unidos, el reconocimiento del liderazgo regional y la naturaleza competitiva, más no complementaria, de las dos economías.

García y Vargas (2013) analizaron el impacto en la balanza comercial y los cambios estratégicos adoptados por México como consecuencia de las políticas proteccionistas aplicadas por Argentina y Brasil. Encuentran que la industria automotriz mexicana tuvo que reencauzar sus exportaciones hacia otros mercados (Asia, África y Europa), a fin de minimizar las afectaciones al sector pero que afectan las relaciones comerciales de los socios.

Con respecto a la comparación de las dos industrias, Martín y González (2013) estudian las políticas de industrialización de los sectores automotrices de ambos países, a partir de los modelos económicos y de industrialización adoptados desde la apertura de las economías. Señalan que en Brasil se han elaborado estrategias sectoriales que han apuntado hacia la eficiencia energética de los vehículos de circulación nacional acordes a las políticas mundiales, el fortalecimiento de la cadena de autopartes donde algunas empresas brasileñas cuentan con capital nacional y la consolidación del mercado automotriz en la región del Mercosur. Por su parte, México a raíz de la apertura económica ha perdido en el fortalecimiento de las cadenas productivas, la industria es de carácter transnacional y no ha existido una política industrial delineada.

Bajo este contexto, el objetivo de este artículo es mostrar los caminos marcadamente diferentes que la industria automotriz ha tomado en México y Brasil para comprobar la existencia de la complementariedad en el marco del intercambio bilateral.

El documento presenta una investigación descriptiva y exploratoria con resultados a partir del análisis de datos estadísticos publicados por las asociaciones nacionales que recaban la información de las industrias automovilísticas de ambos países (AMIA y ANFAVEA). Para ello se ha homogeneizado el criterio de autos ligeros (autos compactos o automóviles y camionetas o autos comerciales ligeros) y vehículos pesados (camiones,

\footnotetext{
${ }^{2}$ En el caso de Brasil se incluye la fabricación y exportación de autos ensamblados y se excluyen aquellos por ensamblar (Completely Knock Down CKD).
}

tractocamiones y omnibuses) ${ }^{2}$, así como los datos de comercio exterior emitidos por sus fuentes oficiales y por la Comisión Económica para América Latina y el Caribe (CEPAL).

El documento se divide en cuatro apartados, además de la introducción y las conclusiones; primero se presentan algunos elementos críticos que permiten entender el funcionamiento de industria automotriz; en los apartados dos y tres se aborda el desempeño, características y los diferentes senderos de las industrias en México y Brasil; finalmente se discute la complementariedad de las industrias a partir de la vinculación comercial, particularmente en el marco del intercambio comercial.

\section{Las cadenas mercantiles globales, algunos elementos críticos}

El actual proceso de apertura comercial mundial, donde impera el libre tránsito de mercancías y de capitales entre los diferentes países y regiones, ha marcado la pauta para importantes transformaciones en el desarrollo de los procesos productivos de las grandes empresas multinacionales, las que extienden su presencia a gran parte de los países del mundo a partir de instrumentos como los flujos de capitales y el comercio, así como en la búsqueda de nuevos sitios de manufactura y sus relaciones con proveedores.

Es la década de los setenta el origen de una nueva era de competencia internacional que modifica los patrones de comercio y producción globales, así como las formas de organización industrial. Caracterizado porque las empresas fragmentan su producción alrededor del mundo aprovechando las comunicaciones, cada vez más confiables y con menores costos, así como el manejo del software y de la información que permitieron disminuir significativamente los costos de coordinación de actividades como la estandarización, la automatización y la intermodalidad del transporte, lo que hace más fácil el movimiento de bienes (Dalle et al. 2013).

Chandler (1978) y Arrighi (1994) plantean que hasta la década de los setenta las grandes corporaciones dominaban la economía global, mantenían el control del capital, del mercado y de los flujos de materias primas, este dominio se basaba en 
una estructura organizativa integrada verticalmente. Pozas (2001) señala al respecto que el nuevo modelo de producción favorece la concentración del capital y la creación de grandes y poderosas empresas globales e incorpora un mayor número de unidades productivas más pequeñas y autónomas a un complejo sistema de subcontratación internacional, donde la permanencia de las empresas va a depender de su capacidad para integrarse al sistema abasteciendo a un cliente importante y de su flexibilidad para cambiar con facilidad de un cliente a otro.

En este mismo sentido Boyer y Freyssenet (2013) señalan que en las últimas décadas han habido muchos cambios en los procesos productivos, que han traído consigo nuevas habilidades, relacionadas con la economía global, y destacan que es a partir de la innovación en los sistemas productivos que se logra el desarrollo de una empresa.

En este sentido, Gereffi (2001) señala que hacia la segunda mitad del siglo XX se produjo una transformación en la forma de organización de la economía internacional; pues en la actualidad el intercambio entre los países centrales y los periféricos se ha hecho más complejo, pues ahora el centro de la producción y de exportación de la manufactura se localiza en países de reciente industrialización del tercer mundo.

En este proceso, cobran relevancia las llamadas cadenas mercantiles global (Global Commodity Chain) definidas por Gereffi y Korzeniewicz (1994) como un sistema de producción integrado que vincula las actividades de las empresas a redes tecnológicas, organizacionales e institucionales que son utilizadas para desarrollar, fabricar y comercializar productos específicos. Estas redes vinculan alrededor de un producto a productores $y$ empresas dentro de una economía global, involucrando la adquisición y organización de insumos, fuerza de trabajo, transporte, distribución y consumo.

En estas cadenas de producción se presentan relaciones de poder y autoridad, lo que permite el control de mercados y precios. De acuerdo con Gereffi (1994), la estructura de gobierno se define a partir de la empresa más poderosa de cada cadena

\footnotetext{
${ }^{3}$ Inicialmente con el ingreso de México al Acuerdo General sobre Aranceles Aduaneros y Comercio (GATT) en 1986 y después con la entrada en vigor del Tratado de Libre Comercio de América del Norte (TLCAN) en 1994.
}

global de producción, la que desempeña el rol central en la coordinación de las redes, hacia adelante y hacia atrás de la cadena productiva. Identifica dos tipos de estructura de gobierno para las cadenas globales de producción: a) Cadenas productivas dirigidas por los productores (producer driven), características de industrias intensivas en capital y tecnología, como la automotriz, donde los grandes fabricantes, comúnmente trasnacionales, son los que juegan los papeles centrales en la coordinación de las redes de producción, controlan y organizan la producción, coordinan los eslabonamientos hacia atrás y hacia delante, organizan la cadena de proveedores, determinan el precio, cantidad y calidad de las mercancías y componentes que se producen y circulan a lo largo de la cadena y b) Cadenas productivas dirigidas por compradores (buyer driven) que refieren a aquellas industrias en las que los grandes detallistas, comercializadores y fabricantes de marcas juegan papeles centrales en el establecimiento de redes de producción descentralizada en una variedad de países exportadores, comúnmente localizados en países en desarrollo.

\section{La industria automotriz en México}

La historia de la industria automotriz en México surge con la llegada de las primeras plantas armadoras, primero con el arribo de Ford en 1925, General Motors en 1935 y Automex (con tecnología Chrysler) en 1938. Estas empresas se instalaron en el Distrito Federal y el Estado de México, con lo que se vio favorecida la región centro del país. El objetivo fue abastecer al mercado interno en aras del modelo de sustitución de importaciones que México experimentaba en aquella época. Posteriormente, con la apertura económica del país ${ }^{3}$, se dio un cambio no sólo en la localización espacial -pues surge con gran ímpetu en esta industria la región fronteriza con Estados Unidos en detrimento de la región centrosino también en el destino de la producción nacional; adquiriendo una clara vocación exportadora; además de la paulatina desregularización (Carbajal, 2015).

Actualmente las empresas ensambladoras de automóviles y camiones ${ }^{4}$ presentes en México son:

\footnotetext{
4 Estas trasnacionales también producen motores: Daimler, Chrysler, Ford, General Motors, Nissan, Renault, Volkswagen, Perkins y Cummins.
} 
Tab. 1

México: Principales variables de la industria automotriz, 2008

\begin{tabular}{|c|c|c|c|c|}
\hline & \multirow[b]{2}{*}{$\begin{array}{l}\text { Unidades } \\
\text { económicas }\end{array}$} & \multirow[b]{2}{*}{$\begin{array}{l}\text { Personal } \\
\text { ocupado }\end{array}$} & \multicolumn{2}{|c|}{ Miles de pesos } \\
\hline & & & $\begin{array}{l}\text { Producción } \\
\text { bruta total }\end{array}$ & $\begin{array}{c}\text { Valor } \\
\text { agregado } \\
\text { censal bruto }\end{array}$ \\
\hline Industria Automotriz en México & 1.977 & 512.937 & 752.875 .589 & 213.006 .240 \\
\hline Fabricación de automóviles y camionetas & 14 & 38.279 & 326.632 .582 & 72.406 .571 \\
\hline Fabricación de camiones y tractocamiones & 21 & 12.626 & 70.264 .089 & 10.557 .819 \\
\hline Fabricación de carrocerías y remolques & 706 & 20.853 & 15.416 .073 & 4.392 .930 \\
\hline Fabricación de motores de gasolina y sus partes para vehículos automotrices & 130 & 39.163 & 59.526 .147 & 17.162 .640 \\
\hline Fabricación de equipo eléctrico y electrónico para vehículos automotores & 297 & 185.722 & 81.828 .080 & 36.217 .123 \\
\hline $\begin{array}{l}\text { Fabricación de partes de sistemas de dirección y de suspensión para vehículos } \\
\text { automotrices }\end{array}$ & 67 & 13.336 & 15.936 .066 & 5.198 .614 \\
\hline Fabricación de partes de sistemas de frenos para vehículos automotrices & 105 & 15.130 & 10.219.297 & 4.152 .506 \\
\hline Fabricación de partes de sistemas de transmisión & 47 & 18.637 & 27.119.707 & 9.780 .983 \\
\hline Fabricación de asientos para vehículos automotores & 126 & 63.293 & 42.669 .649 & 16.973 .314 \\
\hline Fabricación de piezas metálicas troqueladas para vehículos automotrices & 136 & 14.845 & 15.196 .472 & 3.398 .200 \\
\hline Fabricación de otras partes para vehículos automotrices & 328 & 91.053 & 88.067 .427 & 32.765 .540 \\
\hline
\end{tabular}

Fuente: Elaboración propia con datos del INEGI (2009).

a) Automóviles: Chrysler-Fiat, Ford, General Motors, Honda, Toyota, Nissan, Renault, Mazda y Volkswagen;

b) Camiones pesados y autobuses: Daimler, Dina, Freightliner, Giant Motors, Hino Motors, International Navistar, Isuzu, Kenworth, Mercedes-Benz, Scania, Volkswagen/Man, y Volvo (ANPACT, 2014).

La industria automotriz genera $3.0 \%$ del PIB total nacional; más de un millón de empleos directos e indirectos, que representan $1.6 \%$ del empleo total nacional. Para la manufactura, esta industria es un sector clave, pues aporta $17.7 \%$ al producto manufacturero, emplea $11 \%$ de la población ocupada; contribuye con $15.4 \%$ de la producción bruta total, $14.4 \%$ del valor agregado censal bruto y recibe $14.8 \%$ del total de las remuneraciones pagadas en ese sector (INEGI, 2014).

Este sector se ha convertido en el principal generador de divisas, en 2013 las exportaciones automotrices representaron $25.2 \%$ del total de las exportaciones mexicanas con aproximadamente 97 mil 781 millones de dólares (mdd), exportando a más de 100 países y superando a las exportaciones petroleras y a las de equipo y aparatos eléctricos y electrónicos (AMIA, 2014).

Es también uno de los mayores receptores de inversión extranjera directa (IED), entre 1999 y el primer trimestre de 2016 recibió 45,687.5 millones de dólares, cantidad que representó poco más del $21 \%$ de la IED recibida en la manufactura y $10.2 \%$ del total recibido en el país en ese mismo periodo (SE, 2016). En el Tab 1, se presenta la conformación actual de la industria automotriz en México.

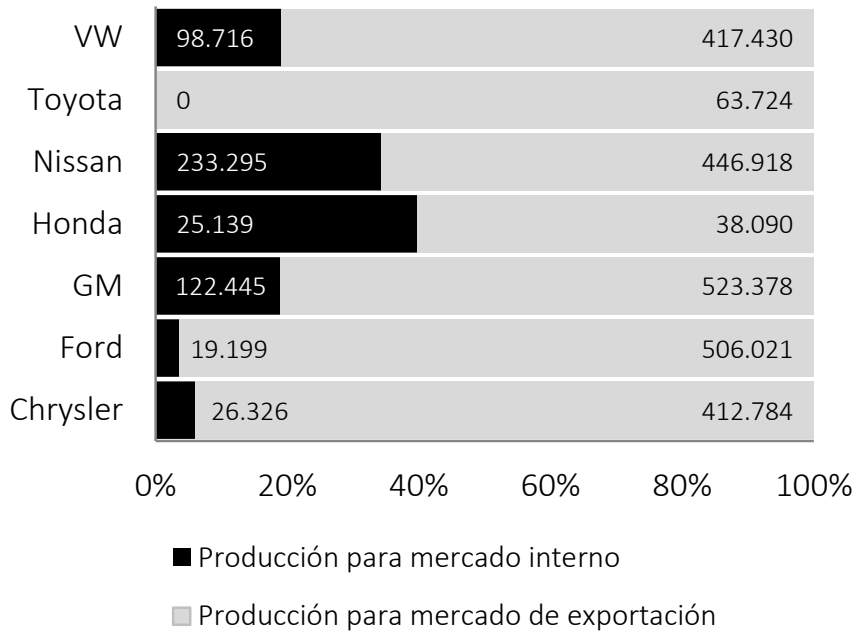

Fig. 1

México: producción de vehículos ligeros empresa y tipo de mercado, 2013

Fuente: AMIA (2013).

En el sector automotriz de México destaca la fabricación de automóviles y camionetas, actividad que emplea $7.5 \%$ del personal ocupado y genera $43.4 \%$ y $34.0 \%$ de la producción bruta y del valor agregado bruto total, respectivamente, del sector a nivel nacional. Así también la fabricación de equipo eléctrico y electrónico para vehículos automotores, pues en esta actividad se ocupa $36.2 \%$ de la población del sector, y se genera $10.9 \%$ de la producción bruta total y $17.0 \%$ del valor agregado censal bruto. Otra 
Tab. 2

Participación porcentual de las exportaciones de unidades de vehículos ligeros por lugar de destino, 2000-2013

\begin{tabular}{|c|c|c|c|c|c|c|c|c|c|c|c|c|c|c|}
\hline & 2000 & 2001 & 2002 & 2003 & 2004 & 2005 & 2006 & 2007 & 2008 & 2009 & 2010 & 2011 & 2012 & 2013 \\
\hline Estados Unidos & 83,7 & 83,6 & 87,7 & 83,7 & 85,6 & 82,7 & 82,4 & 74,6 & 70,8 & 71,2 & 69 & 63,7 & 63,9 & 68 \\
\hline Canadá & 10,3 & 10,2 & 10,1 & 10,6 & 8,1 & 7,1 & 5,6 & 5,5 & 6,8 & 8 & 7,7 & 7,5 & 6,8 & 8 \\
\hline Latinoamérica & 2,1 & 2,2 & 2,2 & 1,4 & 2,4 & 3,4 & 3,9 & 6,3 & 7,3 & 8,4 & 11,7 & 16,1 & 15,5 & 12,7 \\
\hline Brasil & 0,2 & 0,6 & 0,8 & 0,1 & 0,1 & 0,2 & 0,4 & 1,5 & 3 & 3,8 & 4 & 6,2 & 7,6 & 5,7 \\
\hline Asia & 0 & 0 & 0 & 0 & 0 & 0 & 0,1 & 0,7 & 2,2 & 1,9 & 2 & 1,2 & 2 & 2,8 \\
\hline Europa & 3,9 & 3,9 & 3 & 4,2 & 3,9 & 6,8 & 8 & 12,1 & 12,9 & 10,2 & 9,2 & 10,3 & 9 & 5,9 \\
\hline Otros & 0 & 0 & 0 & 0,1 & 0 & 0 & 0 & 0,8 & 0,1 & 0,2 & 0,9 & 2,2 & 1,3 & 1,4 \\
\hline Total & 100 & 100 & 100 & 100 & 100 & 100 & 100 & 100 & 100 & 100 & 100 & 100 & 100 & 100 \\
\hline
\end{tabular}

Fuente: Elaboración propia con datos de AMIA (2013).

actividad que se destaca dentro del sector automotriz en México es la fabricación de motores de gasolina y sus partes pues emplea $7.6 \%$ del personal ocupado y aporta $7.9 \%$ y $8.1 \%$ de la producción bruta total y el valor agregado del sector, respectivamente. México se ha convertido en una plataforma importante de exportación para el sector automotriz, actualmente gran parte de la producción de vehículos ligeros se destina al mercado externo. La Fig. 1 es evidente en este sentido: Chrysler destinó 94\% de su producción al mercado externo, mientras que Ford Motor 96\%, General Motors 81\%, Honda 60\%, Nissan 66\%, Toyota $100 \%$ y Volkswagen $81 \%$ (AMIA 2013).

En 1988 de un total de 505,202 vehículos manufacturados en México, 174,246 fueron destinados al mercado externo lo que significó 34.5\% de su producción total. Para 2013, las cifras cambiaron drásticamente, pues, de 2,933,465 unidades producidas, $2,408,345$ se destinaron al mercado internacional, lo que significó $82.0 \%$ del total (AMIA, 2013).

Los destinos de exportación de la producción automotriz nacional, aun cuando se han diversificado en los años recientes, todavía se concentran en gran parte hacia los Estados Unidos. En el año 2000 Estados Unidos y Canadá en conjunto recibieron 94.0\% de las exportaciones totales de vehículos, Brasil apenas significó $0.2 \%$, Latinoamérica $2.1 \%$ y Europa 3.9\%. Para 2013 se apreciaron algunos cambios significativos en el destino de exportación de vehículos; Estados Unidos recibió 68.0\%, Canadá 8.0\%, Latinoamérica 12.7\%, Brasil 5.7\%, Asia 2.8\% y Europa 5.9\% (véase Tab 2).

la producción de vehículos pesados el mercado de destino es mucho más equilibrada que en los vehículos ligeros. La producción para el mercado interno ha superado a la destinada al mercado internacional principalmente en el periodo de 20002009, sin embargo de 2010-2013 se observó una clara tendencia en priorizar la producción para exportación (véase Fig. 2).

Algunas cifras representativas indican que en el $2000,73.2 \%$ de la producción total de vehículos pesados era destinada al mercado interno y solo el 26.8\% al mercado externo; sin embargo para 2013 existió un cambio significativo; el $28.7 \%$ de la producción se destinó al mercado interno y el $71.3 \%$ al mercado externo. Fue precisamente a partir del 2008 que se empezaron a sentir los efectos devastadores para este sector derivados de la Gran Recesión, que la producción para el mercado externo se recuperó de manera rápida, mientras que el mercado interno más bien se estancó notablemente (véase Fig. 2).

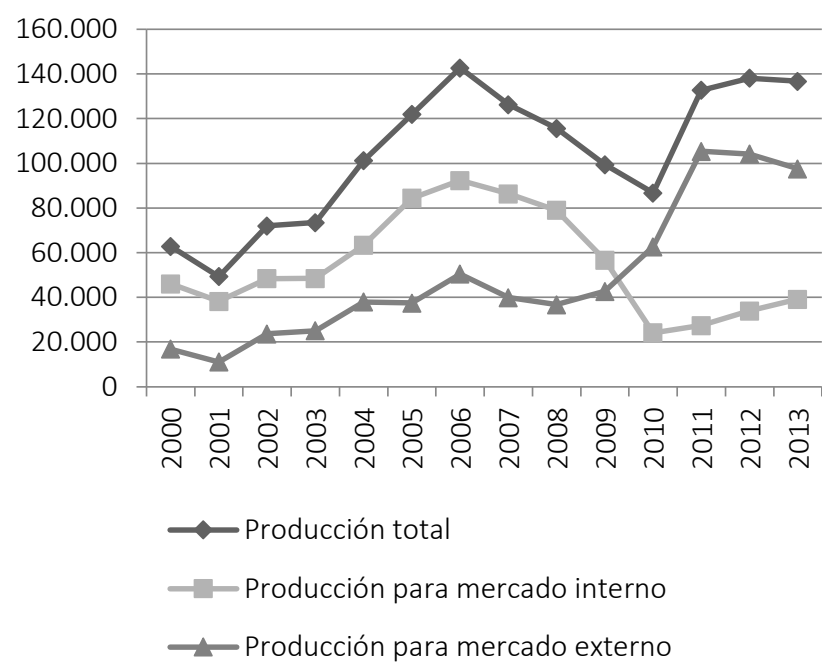

Fig. 2

Producción total de vehículos pesados dividida por tipo de mercado, 2000-2013

Fuente: Elaboración propia con datos del INEGI (2006 y 2011) y ANPACT (2014).

Al igual que en los vehículos ligeros, el principal mercado para los vehículos pesados manufacturados en México es el estadounidense, en ese país se ha 
Tab. 3

Participación porcentual de las exportaciones de unidades de vehículos pesados por lugar de destino, 2000-2013x

\begin{tabular}{|c|c|c|c|c|c|c|c|c|c|c|c|}
\hline & 2000 & 2001 & 2002 & 2003 & 2004 & 2005 & 2006 & 2007 & 2008 & 2009 & 2010 \\
\hline Estados Unidos & 93,8 & 93,8 & 95,2 & 95,2 & 93,6 & 85 & 82,3 & 59,4 & 68,1 & 92,4 & 86,6 \\
\hline Colombia & 0,3 & 1,6 & 1,8 & 2,1 & 3,1 & 8,9 & 10,5 & 20,5 & 10,6 & 2,9 & 6,1 \\
\hline Chile & 2,7 & 2,2 & 0,8 & 1,1 & 1,3 & 1,8 & 1,1 & 2,7 & 3,5 & 0,9 & 2,7 \\
\hline Perú & 0,2 & 0 & 0,1 & 0,2 & 0,2 & 0,4 & 0,5 & 2,8 & 8,7 & 0,9 & 2 \\
\hline Ecuador & 0 & 0,3 & 0 & 0,1 & 0,2 & 0,4 & 0,4 & 0,5 & 1,9 & 1 & 0,9 \\
\hline Venezuela & 0 & 0 & 0,1 & 0,2 & 0,7 & 2,8 & 4,1 & 9,9 & 3,3 & 0,3 & 0,2 \\
\hline Otros & 2,9 & 2,1 & 2 & 1,1 & 0,9 & 0,7 & 1,1 & 4,2 & 3,9 & 1,6 & 1,5 \\
\hline Total & 100 & 100 & 100 & 100 & 100 & 100 & 100 & 100 & 100 & 100 & 100 \\
\hline
\end{tabular}

Fuente: INEGI (2006 y 2011).

concentrado la venta de este tipo de vehículos; algunos otros destinos son Colombia, Chile, Perú, Ecuador y Venezuela (véase Tab 3).

\section{La industria automotriz en Brasil}

Los inicios de la industria automotriz brasileña se ubican con la instalación de la Planta de Ford en 1919 y de General Motors (GM) en 1925. En 1956, el presidente Juscelino Kubitschek creó el Grupo Ejecutivo de la Industria Automovilística, con el objetivo de fomentar la fabricación local de vehículos. Esta industria evolucionó en el marco de las políticas de industrialización por sustitución de importaciones, caracterizadas por un conjunto de incentivos cambiarios, fiscales y crediticios, las cuales permitieron que en la década de los años cincuenta y sesenta se establecieran otras empresas como Mercedes Benz, Volkswagen (VW), Toyota y Chrysler (Guimarães, 1989; CEPAL, 2001). Guimarães (1989), considera que el rápido crecimiento de la producción de automóviles en esta etapa fue atribuido a la existencia de una demanda interna y los controles a la importación desde años anteriores.

Con la apertura comercial, la industria automotriz comenzó una nueva época, a partir del fomento del mercado interno y de la plataforma exportadora dirigida principalmente al Mercosur. Para enfrentar el déficit comercial que fue producto de la depreciación del tipo de cambio y mantener el ritmo de producción, en 2011 se desarrolló el Programa de Inventivos a la Innovación Tecnológica y Densificación de la Cadena Productiva de Vehículos Automotores, comúnmente referido como Inovar-Auto. El objetivo de este programa es aumentar la competitividad, tecnología y seguridad de los vehículos producidos y vendidos en Brasil por medio de la inversión (Ferreira, et al., 2013; Figueroa et al., 2016).

La industria automotriz brasileña está compuesta por automóviles ligeros, vehículos comerciales ligeros, camiones, autobuses, maquinaria agrícola y de carretera ${ }^{5}$ y autopartes (véase Tab. 4).

Tab. 4

Brasil: principales variables de la industria automotriz, 2013

\begin{tabular}{lr}
\hline & Unidades \\
\hline Producción total de unidades & 3.712 .736 \\
Fabricación de automóviles ligeros & 2.954 .279 \\
Fabricación de vehículos comerciales ligeros & 530.901 \\
Fabricación de camiones & 187.002 \\
Fabricación de ómnibus & 45.554 \\
Personal ocupado* & 135.343 \\
Facturación neta (millones de dólares) & 87.294 \\
\hline
\end{tabular}

*Considera exclusivamente las personas con contrato de trabajo firmado con las empresas asociadas de ANFAVEA.

Fuente: ANFAVEA (2016).

Entre las empresas que se dedican a la fabricación de vehículos ligeros y pesados se encuentran: Agrale, Audi, BMW, CAOA, DAF, FCA, Ford, GM, Honda, Hyundai, International, Iveco, Mahindra, MAN, Mercedes-Benz, MMC, Nissan, Peugeot Citroën, Renault, Scania, Toyota, VW y Volvo.

GM, VW y Fiat cuentan con centros de diseño (Salerno, en Álvarez, 2010). A diferencia de México, Brasil cuenta con más empresas transnacionales europeas; además, "GM y Ford tienen una producción con diseños más europeos por lo que las

\footnotetext{
${ }^{5}$ En este análisis y con la finalidad de homogeneizar con los datos de la industria mexicana sólo se excluyen la maquinaria agrícola y de carretera
} 


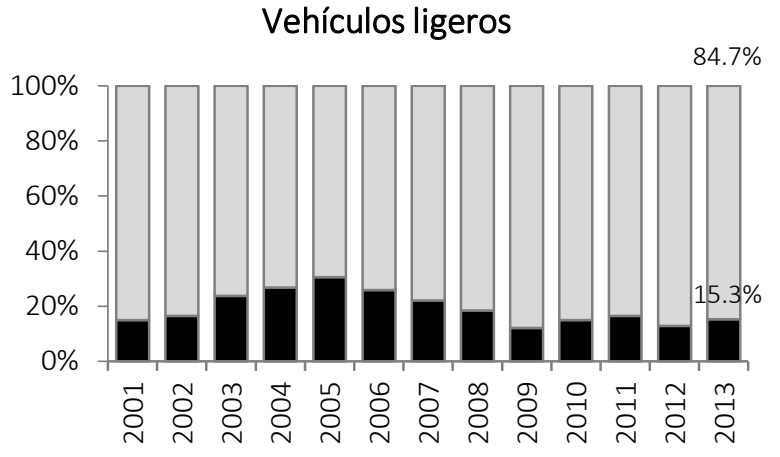

口 Mercado de Exportación $\square$ Mercado interno

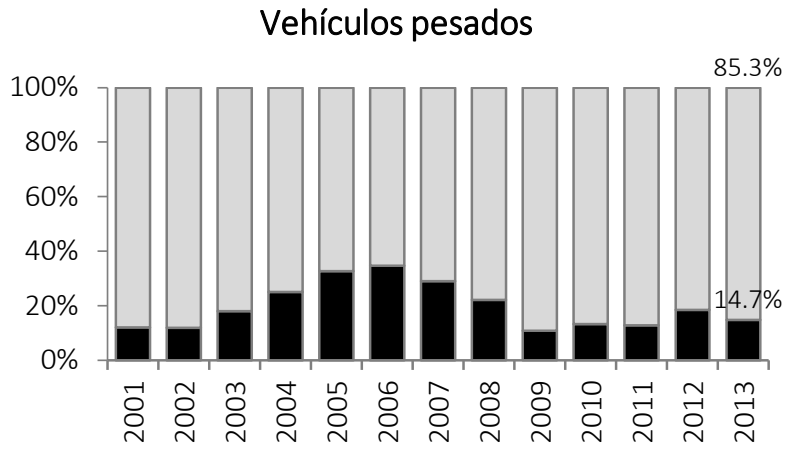

Mercado de Exportación

$\square$ Mercado interno

Fig. 3

Brasil: producción por tipo de mercado de los vehículos ligeros y de los vehículos pesados, 2001-2013

Nota: los vehículos ligeros incluye a los automóviles y vehículos comerciales ligeros, en tanto, los vehículos pesados incluyen los camiones y los omnibuses

Fuente: ANFAVEA (2016).

unidades que producen son pequeñas y económicas" (Álvarez, 2010, p.12).

La industria automotriz brasileña está enfocada en la producción de vehículos ligeros (vehículos ligeros más vehículos comerciales ligeros) antes que en los vehículos pesados (camiones y ómnibus). No obstante, la producción de estas unidades también se ha incrementado en la última década: en 2001 se produjeron 99,197 unidades y en 2013 fueron producidas 227,556 unidades. Al igual que lo que sucede con la fabricación de vehículos ligeros, la mayor parte de la producción se destina al mercado interno y no a la exportación (véase Fig. 3).

Los automóviles ligeros son las principales unidades de exportación de esta industria, a pesar de que la mayor parte de la producción de este rubro se destina al mercado interno, en contraste de lo que sucede con la industria automotriz mexicana. La Fig. 4 muestra la vocación de la industria automotriz brasileña por el mercado interno antes que constituirse como mercado de exportación, diferencia radical con respecto a la vocación exportadora de la industria automotriz mexicana. En los últimos cincos años, el $14 \%$ ha sido exportado, por lo que Figueroa et al. (2016) concuerdan en que la mayor parte de la producción brasileña se destina al mercado interno.

En el año 2001, del total de unidades producidas en Brasil 1,674, 522 unidades, sólo se destinaron a la exportación 248,272 unidades (79.4\% automóviles ligeros, $15.8 \%$ vehículos comerciales ligeros, $2.6 \%$ camiones y $2.1 \%$ omnibuses). Para el año 2013, la producción automotriz ascendió a 3,712,736

unidades, de las cuales 565,111 fueron destinadas a la exportación: $81.6 \%$ automóviles ligeros, $12.5 \%$ vehículos comerciales ligeros, $4.3 \%$ camiones y $1.6 \%$ omnibuses (ANFAVEA, 2016).

Con respecto a los vehículos ligeros, desde el 2007 el principal mercado de exportación es Argentina, en el 2013 absorbió más de 76\% de la producción exportable; en tanto que México sólo recibió 5.2\%. No obstante, en el año 2001, los mercados de exportación se encontraban diversificados: el resto del mundo (33.1\%), México (23.4\%) y Estados Unidos (22.4\%), eran los principales mercados (véase cuadro $5)$.

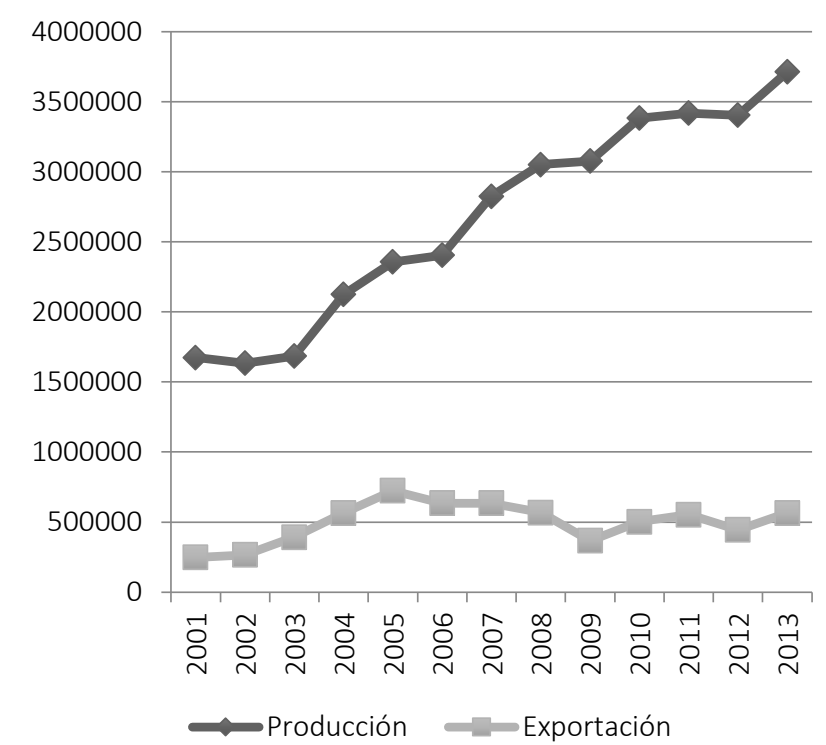

Fig. 4

Brasil: Producción y exportación total de vehículos, 2001-2013 (unidades)

Fuente: ANFAVEA (2016). 
Tab. 5

Brasil: participación porcentual de las exportaciones de vehículos ligeros por lugar de destino, 2001-2013 (unidad de medición miles de millones dólares)

\begin{tabular}{|c|c|c|c|c|c|c|c|c|c|c|c|c|c|}
\hline & 2001 & 2002 & 2003 & 2004 & 2005 & 2006 & 2007 & 2008 & 2009 & 2010 & 2011 & 2012 & 2013 \\
\hline Estados Unidos & 22,4 & 24,8 & 15,4 & 4,4 & 3,8 & 3,1 & 0,7 & 0,1 & 0,1 & 0,1 & 0,0 & 0,0 & 0,1 \\
\hline México & 23,4 & 33,4 & 33,5 & 28,3 & 20,6 & 20,9 & 13,9 & 9,7 & 11,5 & 10,7 & 6,9 & 6,4 & 5,2 \\
\hline China & & & & & & 0,4 & 0,5 & 0,0 & 0,0 & 0,0 & 0,0 & 0,0 & 0,0 \\
\hline Argentina & 15,5 & 6,3 & 19,1 & 30,2 & 29,1 & 31,6 & 36,1 & 45,1 & 48,4 & 57,7 & 70,6 & 66,8 & 76,2 \\
\hline Unión Europea & 5,6 & 3,7 & 3,4 & 3,2 & 11,9 & 10,5 & 11,5 & 15,0 & 15,7 & 8,1 & 1,6 & 0,5 & 0,7 \\
\hline Corea del Sur & & & & & & 0,8 & 0,1 & 0,0 & 0,0 & 0,0 & 0,0 & 0,0 & 0,0 \\
\hline Japón & & & & & & 0,0 & 0,0 & 0,1 & 0,0 & 0,0 & 0,0 & 0,0 & 0,0 \\
\hline Otros & 33,1 & 31,8 & 28,7 & 33,9 & 34,6 & 32,5 & 37,1 & 30,1 & 24,3 & 23,4 & 20,9 & 26,2 & 17,7 \\
\hline & 100 & 100 & 100 & 100 & 100 & 100 & 100 & 100 & 100 & 100 & 100 & 100 & 100 \\
\hline
\end{tabular}

Fuente: ANFAVEA (2014).

\section{El sector automotriz en México y Brasil. ¿Complementariedad en el marco del intercambio comercial?}

La industria automotriz no sólo tiene importancia en el intercambio bilateral entre México y Brasil, sino que presenta un componente fundamental para la balanza comercial de los dos países. Por ejemplo, a diciembre de 2013 para Brasil los automóviles de pasajeros fueron el segundo bien de importación dentro de todo su comercio; en este segmento, México fue el segundo socio comercial con 1,942 mdd (MDICE, 2014) ${ }^{6}$. Para México, las exportaciones manufactureras al primer semestre de 2014 representaron el $83.1 \%$, de este porcentaje la participación de la industria automotriz fue de $26.9 \%$.
A nivel bilateral, la importancia del intercambio comercial también radica en el comercio del sector industrial, particularmente del sector automotriz. De estos productos, la fabricación de vehículos ligeros, pesados y autopartes constituyen componentes fundamentales en la relación comercial (véase Fig. 5). De hecho, históricamente el intercambio automotriz ha sido el componente principal de la relación comercial de ambos países, pese a que el mercado mexicano no tiene la importancia que posee Argentina, ya que si bien llegó a ocupar hasta un 11.9\% de participación de las exportaciones en 2009, en 2013 fue la mitad de esta participación (véase Tab. 5).
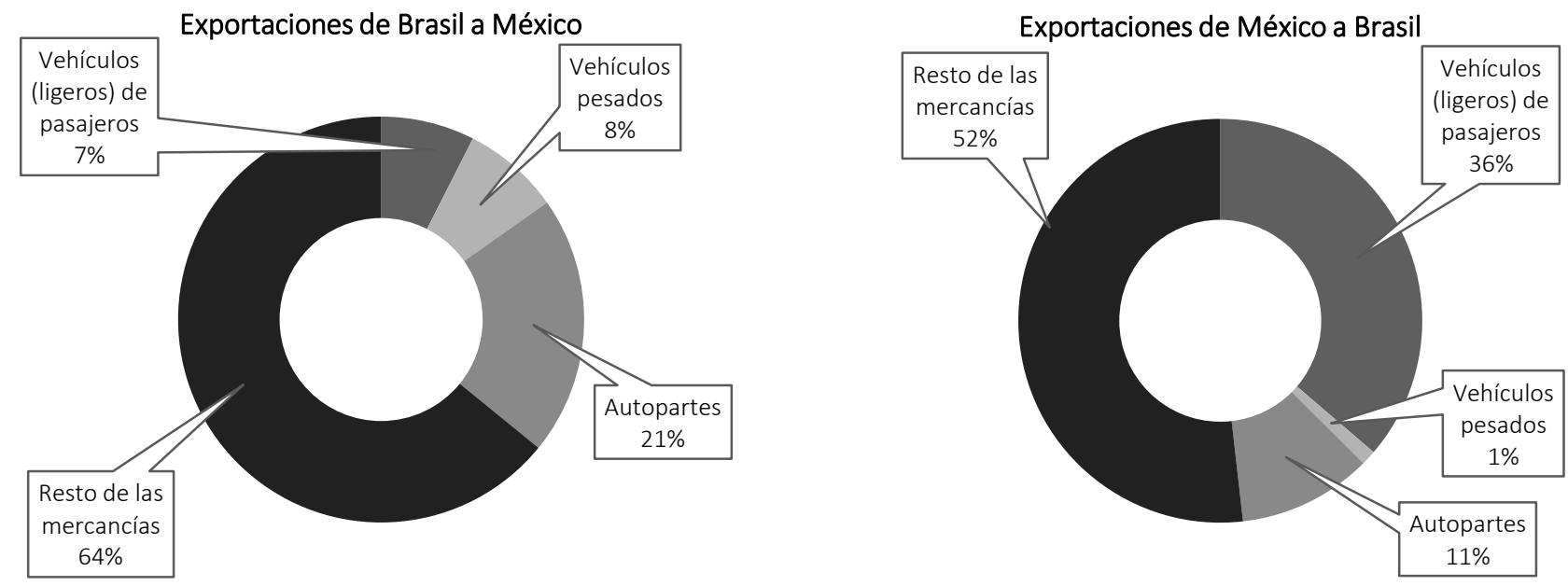

Fig. 5

Exportaciones bilaterales, 2013

Fuente: Comisión Económica para América Latina y el Caribe (CEPAL, 2014).

\footnotetext{
${ }^{6}$ MDICE, Ministerio de Desarrollo, Industria y Comercio Exterior
} 


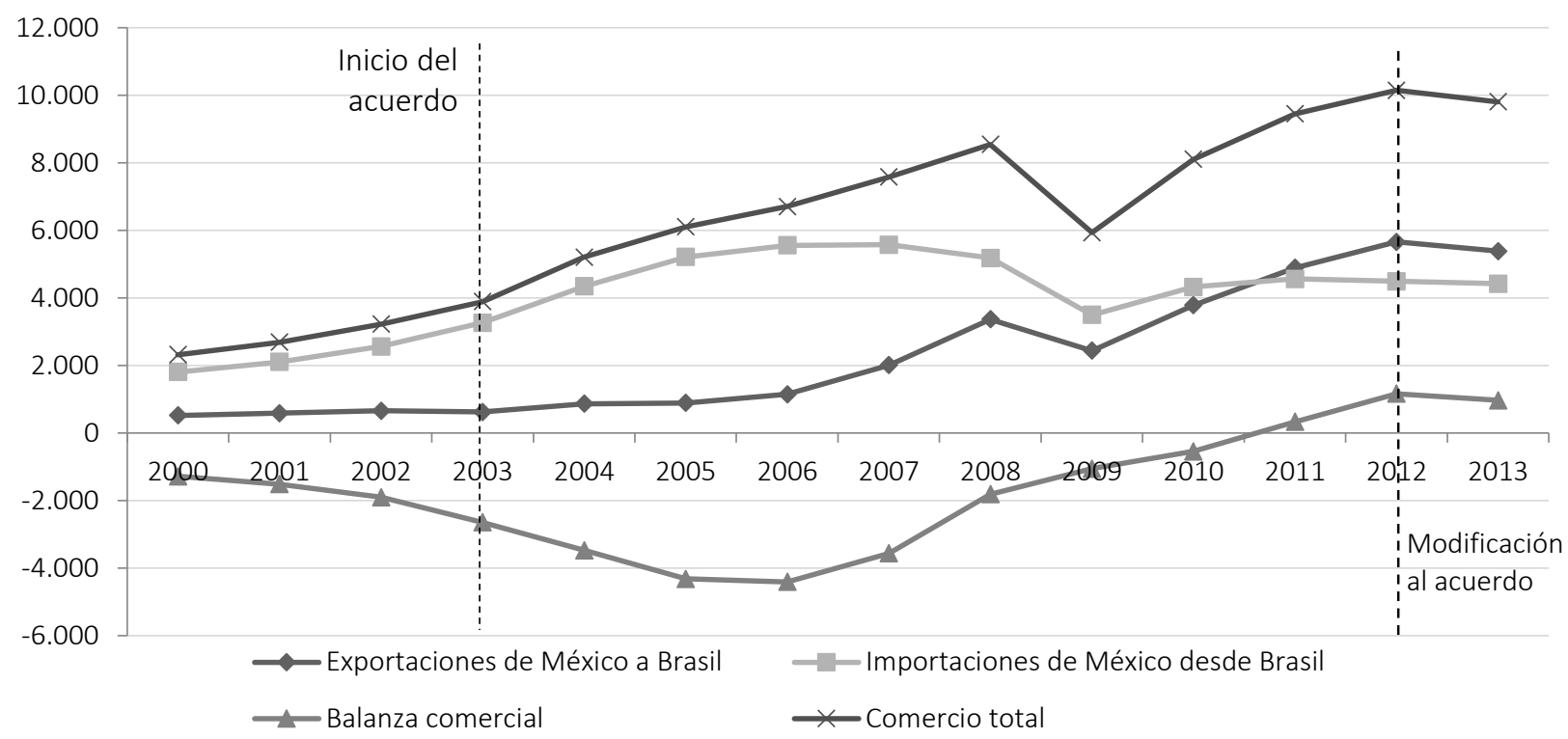

Fig. 6

Intercambio comercial Brasil-México (millones de dólares)

Fuente: Banco de México (2014).

En el año 2002, México y Brasil firmaron el ACE No. $55^{7}$, el cual regula el comercio en el sector automotriz y de sus sectores productivos. Los vehículos contemplados en el acuerdo son: automóviles, vehículos de carga, autobuses de pasajeros, carrocerías, remolques, semirremolques, tractores agrícolas, cosechadoras, maquinaria agrícola, maquinaría vial autopropulsada. En tanto que las autopartes son: piezas, conjuntos, subconjuntos y neumáticos necesarios para la producción de vehículos.

El acuerdo estableció la aplicación de disposiciones comerciales y legales compatibles con el sistema multilateral de comercio hacia las importaciones. Debido a que el acuerdo contemplaba el libre comercio en el sector automotriz, los dos países establecieron un periodo de transición desde la entrada en vigor del acuerdo hasta 2011, conforme a lo plasmado en el apéndice bilateral ${ }^{8}$. Es decir, los países negociaron cupos anuales bilaterales para la entrada de vehículos sin pago de arancel, donde en el primer año se ofreció un acceso preferencial para 396

\footnotetext{
${ }^{7}$ El ACE No. 55 regula el comercio en el sector automotriz entre México y el Mercosur pero existen apéndices bilaterales para cada uno de los países miembro de este bloque de integración regional.

${ }^{8}$ Originalmente, el ACE 55 contemplaba el periodo de transición desde la entrada en vigencia y el libre comercio hasta el 5o año.
}

mil vehículos hasta llegar a 534 mil unidades en el quinto año (ACE 55, 2002).

Sin embargo, la producción industrial de Brasil está enfocada en los autos ligeros, su venta al mercado interno y como principal bien de exportación al mercado regional (Mercosur). En tanto que México prioriza la producción de vehículos hacia el mercado norteamericano.

A principios de 2012, Brasil solicitó a México una revisión del ACE 55, en virtud de la balanza negativa que estaba registrando, particularmente en los últimos meses de 2011 y los primeros de 2012 (véase Fig. 6). El argumento tenía una justificación: desde la entrada en vigor del acuerdo, los vehículos de pasajeros incrementaron su peso en las exportaciones mexicanas, de $2.9 \%$ en 2003 a $48 \%$ registrado en 2013. Con ello, el volumen de venta se incrementó en más de 155 mil unidades vendidas en 2011 (Morales; Serrano, 2012). Es importante mencionar que, en tanto México importó más de 2 mil mdd en vehículos, Brasil sólo exportó 327 mdd en autos y autopartes ${ }^{9}$.

Sin embargo, en diciembre de 2007 se firmó el primer protocolo adicional al ACE 55, el cual amplió los periodos de transición y estableció el libre comercio hasta el año 2011 (DOF, 2007).

${ }^{9}$ Entre los modelos que Brasil le compra a México se encuentran: March, Tiida y Sentra (Nissan), Fusion (Ford), Fiat 500, Jetta (Volkswagen). 
Para la revisión del acuerdo, Brasil alegó el creciente déficit en el comercio de vehículos ligeros. Más aún, junto al déficit registrado con México, la economía brasileña presenta, desde el año 2009, un saldo negativo en el comercio de vehículos automotores, remolques y carrocerías. Este saldo se incrementó de 3 mil mdd a 8.2 mil mdd en 2011 (IPEA, 2012) ${ }^{10}$.

El argumento presentado por el país sudamericano se basó en la necesidad de devolver la competitividad a la industria brasileña, perjudicada por la fuerte apreciación del real ${ }^{11}$ y que condujo al incremento de las importaciones de autos mexicanos más baratos. Ante el déficit comercial, la idea del gobierno era otorgar mayor protección al mercado interno y a la industria. Desde octubre de 2011, Brasil había incrementado el IPI, adicional de 30 puntos porcentuales para vehículos importados desde afuera del Mercosur y México, para hacer frente al saldo comercial negativo, principalmente de la competencia asiática.
Sin embargo, a la economía mexicana no le convenían las negociaciones porque tenían que establecerse incrementos en las cuotas de importación de vehículos ligeros, adelantar la apertura de vehículos pesados -producción en la cual Brasil sería más competitivo que México- e incrementar el contenido regional de vehículos ligeros (SE, 2012).

EI ACE 55 les permite a las automotrices instaladas en México ofrecer sus autos a precios más competitivos en el mercado brasileño. Asimismo, las armadoras brasileñas requieren de la importación de autos y autopartes mexicanas. Recuérdese que ambos países mantienen armadoras comunes, entre las que se encuentran: Ford, Honda, Volkswagen, Nissan, Mazda ${ }^{12}$.

Después de un mes de negociaciones, donde inclusive se llegó al temor de perder el acuerdo, los negociadores gubernamentales de ambos países acordaron la adopción de cuotas libres de arancel y

Tab. 6a

Exportaciones de automóviles y autopartes de México a Brasil (millones de dólares)

\begin{tabular}{|c|c|c|c|c|c|c|c|c|c|c|}
\hline & \multicolumn{2}{|c|}{2009} & \multicolumn{2}{|c|}{2010} & \multicolumn{2}{|c|}{2011} & \multicolumn{2}{|c|}{2012} & \multicolumn{2}{|c|}{2013} \\
\hline & Valor & $\%$ & Valor & $\%$ & Valor & $\%$ & Valor & $\%$ & Valor & $\%$ \\
\hline Exportaciones totales & 2438 & 100 & 3781 & 100 & 4891 & 100 & 5575 & 100 & 5387 & 100 \\
\hline Exportaciones automotrices & 896 & 36,8 & 1466 & 38,8 & 2413 & 49,3 & 2539 & 45,5 & 2310 & 42,9 \\
\hline $\begin{array}{l}\text { Automóviles de turismo y demás para el transporte } \\
\text { de personas }\end{array}$ & 844 & 34,6 & 1380 & 36,5 & 2265 & 46,3 & 2240 & 40,2 & 1932 & 35,9 \\
\hline $\begin{array}{l}\text { Vehículos automóviles para el transporte de } \\
\text { mercancías }\end{array}$ & 7 & 0,3 & 0 & 0,0 & 7 & 0,1 & 47 & 0,9 & 34 & 0,6 \\
\hline Partes y accesorios de vehículos automóviles & 45 & 1,9 & 85 & 2,3 & 141 & 2,9 & 251 & 4,5 & 345 & 6,4 \\
\hline
\end{tabular}

Fuente: Secretaría de Economía (2014) con datos del Banco de México.

Tab. 6b

Exportaciones de automóviles y autopartes de Brasil a México

\begin{tabular}{|c|c|c|c|c|c|c|c|c|c|c|}
\hline & \multicolumn{2}{|c|}{2009} & \multicolumn{6}{|c|}{2010} & \multicolumn{2}{|c|}{2011} \\
\hline & Valor & $\%$ & Valor & $\%$ & Valor & $\%$ & Valor & $\%$ & Valor & $\%$ \\
\hline Exportaciones totales & 3495 & 100 & 4327 & 100 & 4562 & 100 & 4495 & 100 & 4421 & 100 \\
\hline Exportaciones automotrices & 802 & 23,0 & 938 & 21,7 & 743 & 16,3 & 655 & 14,6 & 714 & 16,1 \\
\hline $\begin{array}{l}\text { Automóviles de turismo y demás para el transporte } \\
\text { de personas }\end{array}$ & 514 & 14,7 & 620 & 14,3 & 384 & 8,4 & 330 & 7,3 & 331 & 7,5 \\
\hline $\begin{array}{l}\text { Vehículos automóviles para el transporte de } \\
\text { mercancías }\end{array}$ & 98 & 2,8 & 98 & 2,3 & 125 & 2,7 & 82 & 1,8 & 144 & 3,3 \\
\hline Partes y accesorios de vehículos automóviles & 190 & 5,4 & 220 & 5,1 & 234 & 5,1 & 243 & 5,4 & 239 & 5,4 \\
\hline
\end{tabular}

Fuente: Secretaría de Economía (2014) con datos del Banco de México.

\footnotetext{
10 Instituto de Investigación Económica Aplicada de Brasil (IPEA por sus siglas en portugués).

${ }^{11}$ De acuerdo con la Federal Reserve System (FED), el tipo de cambio spot del real/dólar estadounidense se apreció en los periodos enero-julio 2011, de 1.67 a 1.56 y, posteriormente, entre diciembre de 2011 y febrero de 2012, de 1.83 a 1.71 reales/dólar (FED, 2012).
}

\footnotetext{
12 Por supuesto, las presiones de esta empresas fueron inmediatas, particularmente la de ésta última, quien con una inversión de 500 mdd en el bajío mexicano, señaló que de modificarse el acuerdo, buscaría otros mercados de diversificación (CNN Expansión, 2012).
} 
de medidas sobre el contenido regional de vehículos ligeros. Con respecto a la primera medida, el acuerdo estableció un régimen temporal incremental para el nivel de exportaciones de vehículos ligeros libre de arancel, por un periodo de tres años. Las cuotas establecidas fueron: 1.45 mil mdd, 1.56 mil mdd y 1.64 mil mdd. Después de este periodo se regresará al libre comercio suscrito originalmente en el acuerdo. Con respecto al contenido regional se acordó incrementar de 30 a 35\% a lo largo del primer año $y$, a partir del quinto año, aplicar un 40 por ciento (SE, 2012).

El comercio en este sector se vio afectado, principalmente para la economía mexicana, ya que a raíz de la modificación al ACE $55^{13}$, se aplicaron los cupos al comercio señalados anteriormente, para después dar paso al libre comercio. Como se observa en el cuadro $6 a$, el $46.3 \%$ de las exportaciones mexicanas en 2011 eran automóviles ligeros. De hecho, es el principal producto de exportación hacia la economía brasileña, pero como consecuencia del restablecimiento de los cupos, el porcentaje de autos exportados cayó hasta un 35.9\% en 2013. Este producto fue el más afectado con respecto a partes automotrices y vehículos de carga.

En el caso de la economía brasileña, pareciera que la modificación del acuerdo no mejoró ni sus saldos comerciales, ni el incremento en sus exportaciones ligadas al sector automotriz. El cuadro $6 \mathrm{~b}$ muestra que los vehículos de turismo no recuperaron el nivel que tenían previo al diferendo comercial, aunque las exportaciones de vehículos pesados y autopartes se incrementó.

La asignación de los cupos de exportación a Brasil fue establecida por la Secretaría de Economía, dirigida a las empresas de la industria automotriz establecidas en México y que cumplan con uno de los siguientes supuestos: manufacturar al menos $40 \mathrm{mil}$ nuevos vehículos en México, contar con registro de empresa productora de vehículos ligeros, ser empresas que se encuentren realizando inversiones para la manufactura de al menos 40 mil vehículos nuevos en México; y que al menos en los dos últimos años hayan realizado exportaciones a Brasil.

Por lo tanto, en primera instancia, los cupos fueron asignados de acuerdo a una cuota parcial que

\footnotetext{
${ }^{13}$ En ese mismo año, Argentina también solicitó una revisión al ACE 55, en el cual se establecieron también cuotas comerciales: 575 mdd, 625 mdd y 1,875 mdd.
}

abarcó del 19 de marzo al 8 de abril de 2012. En dicho acuerdo, Nissan, Chrysler y Ford fueron las tres principales empresas que participaron, con montos de 90, 83 y 55 mdd, respectivamente (DOF, $26 / 03 / 12)^{14}$. Sin embargo, por acuerdo de ambas naciones, se modificó el periodo de la asignación de cupos (véase Tab. 7). En dicha reasignación, Nissan continuó siendo mayormente beneficiada, seguida por Ford y Volkswagen.

Tab. 7

Asignación de cupos de exportación a Brasil (millones dólares)

\begin{tabular}{ccc}
\hline Empresa & $\begin{array}{c}\text { Saldo del cupo para el } \\
\text { periodo marzo 2012- } \\
\text { marzo 2013 }\end{array}$ & $\begin{array}{c}\text { Cupo para cada periodo: } \\
\text { marzo 2013-marzo 2014 } \\
\text { y marzo 2014-marzo }\end{array}$ \\
\hline Chrysler & 173,83 & 2015 \\
Ford & 209,14 & 256,83 \\
GM & 186,08 & 264,14 \\
Honda & 40,21 & 226,58 \\
Nissan & 238,98 & 105,51 \\
Volkswagen & 219,04 & 328,98 \\
BMW & 1,63 & 264,04 \\
BRP & 0,75 & 1,63 \\
EDAG & 0,98 & 1,31 \\
\hline
\end{tabular}

Fuente: DOF (30/04/2012).

En este nuevo acuerdo se precisaron puntos importantes; entre ellos, el seguimiento al ejercicio de los cupos asignados, el no ejercicio de los cupos y la incorporación de nuevos exportadores. Con respecto al no ejercicio de los cupos, éstos podrán ser redistribuidos de acuerdo con un prorrateo con base en las exportaciones a Brasil realizadas de marzo a noviembre, entre las empresas solicitantes. Además, las empresas que no hayan ejercido en su totalidad el cupo asignado, su siguiente cuota será reducida en un monto no mayor al 10\% (DOF, 30/04/12). En tanto que los nuevos exportadores deberán ser empresas que realicen inversiones en el país para la construcción de plantas de ensamblaje y/o que no hayan sido exportadores a Brasil.

De acuerdo con lo establecido por la Secretaría de Economía (DOF, 15/01/14) durante el año 2013, el monto de asignación a los nuevos miembros fue de 110 mdd, mientras que para 2014 es de 190 mdd. Esta última cantidad, sin embargo, ha sido distribuida entre nuevas empresas y empresas exportadoras: Nissan (89 mdd), North Pole Star (3.9 mdd), Chrysler (19 mdd), Ford (24.4 mdd), General Motors (16.2 mdd), Honda (16.5 mdd) y Volkswagen (20.1 mdd). El cupo no utilizado ascendió a 40.4 mdd, los cuales

\footnotetext{
${ }^{14}$ Diario Oficial de la Federación (DOF).
} 
fueron distribuidos entre las siguientes empresas: Chrysler (7.9 mdd), Ford (10.2 mdd), General Motors (6.7 mdd), Honda (6.9 mdd) y Volkswagen (8.4 mdd).

Para el caso brasileño, el Ministerio de Desarrollo, Industria y Comercio Exterior sólo menciona que las empresas que se hagan acreedoras a las cuotas de exportación hacia México deben obtener el Certificado de Cuotas para empresas exportadoras del Banco de Brasil, S.A. (DOU, 03/04/12) ${ }^{15}$. En el caso del primer año (periodo de marzo de 2012 a marzo de 2013), la cuota de exportación se dividió en un $20 \%, 60 \%$ y $20 \%$. La primera cuota correspondiente a 290 mdd, fue repartida entre 10 empresas en partes iguales, es decir, cada empresa participó con 29 mdd: Fiat, Ford, General Motors, Honda, Iveco, Man, Mercedes-Benz, Renault, Toyota y Volkswagen (DOU, 03/04/12).

La siguiente cuota del 60\% (870 mdd) fue repartida de acuerdo con las exportaciones realizadas a México en los tres últimos años. De acuerdo con el cuadro 8, Volkswagen fue la empresa mayormente beneficiada con 355 mdd, seguida por Ford (147 mdd) y Renault (126 mdd). La última parte de la cuota (20\%) sería distribuida a solicitud de los nuevos exportadores. Además, el acuerdo estableció que las cuotas no utilizadas hasta el 7 de diciembre de 2012 podrían ser redistribuidas ente otras empresas.

\section{Tab. 8}

Distribución de la cuota de exportación a México, marzo 2012-2013

\begin{tabular}{ccc}
\hline Empresa & $\begin{array}{c}\text { Valor en millones } \\
\text { de dólares }\end{array}$ & Porcentaje \\
\hline Fiat & 10,7 & 1,2 \\
Ford Motor & 147,0 & 16,9 \\
GM & 89,8 & 10,2 \\
Honda & 112,2 & 12,9 \\
Man Latin America & 7,8 & 0,8 \\
Industria & 19,3 & 2,2 \\
Peugeot-citroen & 126,4 & 14,5 \\
Renault & 1,0 & 0,1 \\
Toyota & 355,4 & 40,8 \\
Volkswagen & & \\
\hline
\end{tabular}

Fuente: DOU (03/04/12).

Para el segundo periodo, es decir, de marzo del 2013 a marzo del 2014, la asignación de las cuotas por parte del ministerio brasileño (1,560 mdd) fue igualmente distribuida en porcentajes del 20\% (312 mdd), 60\% (936 mdd) y 20\% (312 mdd).

El primer $20 \%$ fue distribuido entre las mismas empresas que el primer año, con los mismos porcentajes de participación. El 60\% fue dividido de forma proporcional, considerando la cantidad exportada por la empresa en los últimos tres años y la cantidad exportada a México. El 20\% restante sirvió de reserva para el gobierno brasileño y pudo ser distribuido entre las empresas que así lo requiriesen para exportar mayores volúmenes, o bien, para nuevos exportadores.

Como consecuencia del ajuste de la balanza comercial, no sólo con México, en el 2011 el gobierno brasileño comenzó Inovar-Auto, el cual procura compensar la pérdida de competitividad de la producción nacional, cubrir el avance de los autos asiáticos, mexicanos y europeos, incentivar las inversiones en el mercado interno y redefinir su política de integración. Inovar-Auto promueve cambios en la forma de medir el contenido local y su antecedente inmediato fue el incremento del IPI para los vehículos extrazona (excepto los acordados en los ACE de Argentina, Uruguay y México, incluidos en la cuota del acuerdo comercial). Este régimen consiste en una reducción del IPI en puntos porcentuales y concede como beneficio el crédito supuesto del IPI, condicionado a la atención de ciertos requisitos, como la inversión en I\&D, ingeniería, tecnología industrial básica y capacitación a proveedores (Ferrerira, et al., 2013).

De acuerdo con Figueroa et al. (2016), el impacto de las inversiones de Inovar-Auto son diferentes: algunas empresas contemplaban la inversión como estrategia del crecimiento del mercado regional y otras se han visto forzadas por el Programa para producir localmente y ante la discriminación de importaciones. En el caso de las empresas tradicionales, éstas responden una tendencia global de inversión hacia países emergentes. Se estima que esta inversión es cercana a los 1,500 millones de dólares para plantas de motores de Fiat, Nissan, Ford, Toyota, Chery. Por su parte, Volkswagen, PSA y Volvo están en proceso de ampliación y GM construye una planta de transmisiones.

Quizás el impacto más significativo está en los nuevos inversionistas chinos: 2 plantas para vehículos ligeros, 4 para caminos y JAC Motor para ambos tipos, así como el ingreso de Hyundai Motors. Actualmente se encuentran inscritas 46 empresas de las cuales 21

\footnotetext{
${ }^{15}$ Diario Oficial de la Unión (DOU).
} 
son fabricantes, 13 importadoras y 12 corresponden a proyectos de inversión.

\section{Conclusiones}

Indudablemente la industria automotriz se ha convertido en una de las actividades más importantes tanto en México como en Brasil, esto se refleja en la participación que tiene en el producto interno bruto total y manufacturero, así como en la generación de empleo en ambos países.

Sin embargo, la industria automotriz ha tomado caminos con diferencias en estos dos países, en el sentido de que Brasil ha dado prioridad al fortalecimiento de su mercado interno, pues claramente la producción de ese país se destina principalmente al abasto del mercado nacional tanto en vehículos ligeros como pesados; mientras que en México el sector tiene una cantidad exportadora muy importante, pues cerca del $80 \%$ de la producción de vehículos ligeros y $71 \%$ de vehículos pesados se destina al mercado internacional.

Aún cuando en ambos países se han implementado diversos programas y políticas de apoyo para la industria automotriz, en ninguno de ellos se ha logrado, a la fecha, consolidar una industria nacional, que incorpore capitales nacionales a los principales eslabones de la cadena productiva.

La cadena productiva automotriz en ambos países está bien integrada, sin embargo, son las grandes trasnacionales las principales proveedoras de partes para el ensamble de vehículos, dejando a los capitales nacionales la proveeduría de partes con menor valor agregado.

La consolidación de la cadena global del sector automotriz permitió la negociación de acuerdo comercial bilateral. EI ACE 55 funcionó como un acuerdo favorable para la economía brasileña desde su inicio hasta la incorporación al libre comercio. Una vez que fueron eliminadas las restricciones arancelarias, la relación comercial fue favorable a las exportaciones mexicanas, beneficiada por la revalorización del tipo de cambio brasileño.

Con la modificación del acuerdo y con el restablecimiento de cuotas de exportación, ambas economías han perdido en la relación comercial: Brasil no se ha repuesto del déficit comercial, ni tampoco ha logrado retomar el nivel de sus exportaciones de transporte de turismo; México tampoco ha recuperado el nivel de exportación de sus vehículos ligeros. En resumen, la modificación al acuerdo cumplió su propósito de frenar el ingreso de vehículos producidos en México a Brasil. En tanto que, a nivel de las ensambladoras, las grandes empresas establecidas en México tendrán que conformarse con las cuotas de exportación asignadas por la autoridad, con la esperanza de que el mercado brasileño sea capaz de absorber los vehículos de fabricación mexicana.

Por lo tanto, vale la pena cuestionarse ¿Existe la complementariedad en el marco del intercambio bilateral? La evidencia apunta que la vocación exportadora del sector automotriz en México busca la diversificación de mercados. La economía brasileña es una alternativa en la búsqueda de nuevos mercados para la industria automotriz establecida en México, a lo que se suma la tendencia del consumo interno de unidades y autopartes en el mercado brasileño. La caracterización de ambas industrias hace suponer una natural complementariedad de los mercados: México produce y exporta a Brasil suficientes unidades de vehículos ligeros que demanda el mercado brasileño. No obstante, el propio avance comercial y, más aún, la dinámica de ambas economías evoluciona más hacia una competitividad que ha distorsionado la balanza comercial de Brasil.

Los últimos datos mostrados por el sector automotriz en México consolidan su posición competitiva global (como 4 o exportador mundial), lo que significa que este sector seguirá buscando mercados de colocación de sus productos y seguramente irá más allá de la respuesta brasileña; la prueba está en que a partir del primer semestre de 2015 México ha superado a Brasil en la producción de vehículos (Carbajal; Vergara, 2015).

\section{Referencias}

- ACE 55. (2002) Acuerdo de Complementación Económica entre México y el Mercado Común del Sur (Mercosur). Disponible en: http://www.sice.oas.org/Trade/MERCOSURMexACE54/ME RMex_s.asp. Consultado en diciembre de 2014.

- Álvarez, L. (2010) Industria automotriz en México y en Brasil: una comparación de resultados después de la crisis económica de 2008. XV Congreso Internacional de Contaduría, Administración e Informática. México, Distrito Federal. Disponible en: http://congreso.investiga.fca.unam.mx/docs/xv/docs/174.p df._Consultado en diciembre de 2014. 
- ARRIGHI, G. (1994) The Long Twentieth Century. Verso: Nueva York.

- Asociación Mexicana de la Industria Automotriz - AMIA (2013) Información Estadística. Boletín de Prensa, Diciembre 2013.

Disponible

en: http://www.amia.com.mx/descargarb.html. Consultado en diciembre de 2014.

.(2014) Información Estadística. Boletín de Prensa, Diciembre 2014.2 Disponible en: http://www.amia.com.mx/descargarb.html. Consultado en diciembre de 2014.

- Associação Nacional dos Fabricantes de Veículos Automotores (ANFAVEA). (2015). Estatísticas. Anuário da Indústria Autonomobilística brasileira. 2015. Disponible en: http://www.anfavea.com.br/tabelasnovo.html. Consultado en diciembre de 2014.

- Asociación Nacional de Productores de Autobuses, Camiones y Tractocamiones (ANPACT).(2014). Boletín estadístico mensual. 2014. Disponible en: http://www.anpact.com.mx/. Consultado en noviembre de 2014.

- Banco de México (2014) Balanza de pagos. 2014. Disponible en:

http://www.banxico.org.mx/Sielnternet/consultarDirectori olnternetAction. do?accion $=$ consultarCuadro\&idCuadro $=C E$ $85 \&$ sector=1\&locale=es. Consultado en octubre de 2014.

- BOYER, R. FREYSSENET, M. (2003) "Los modelos productivos". Fundamentos. Versión castellana, Madrid.

- CARBAJAL, Y. (2015) Evolución, condiciones actuales y retos del sector automotriz en México y en el Estado de México. UAEM. Toluca.

- CARBAJAL, Y.; VERGARA, R. (2015) El sector automotriz en México. Una revisión a los datos de 2014 - abril de 2015. Economía Actual, Revista de Análisis de Coyuntura Económica, v. 8, n. 3, p. 15-20.

- ChANDlER, A. (1978) "The United States: Evolution of Enterprise", The Cambridge Economic History of Europe, vol. 7, parte 2, Cambridge University Press.

- Comisión Económica para América Latina y el Caribe (CEPAL) (2001). El Nuevo Régimen Automotor, Documento Informativo, n. 40. Febrero 2001.

(2014) Exportaciones e importaciones de bienes por categoría de productos, según destino/origen. 2014. Disponible en: http://www.cepal.org/comercio/SIGCl/. Consultado en octubre de 2014

- CNN Expansión. México duda de Brasil en pacto comercial (2012). CNN Expansión, Sección Economía. 2012. Disponible en:

http://www.cnnexpansion.com/economia/2012/02/28/me xico-a-salvar-pacto-con-brasil. Consultado en noviembre de 2014.

- DALLE, D.; V. FOSSATI y F. LAVOPA (2013) "Política industrial: ¿el eslabón perdido en el debate de las Cadenas Globales de Valor?", Revista Argentina de Economía Internacional, Núm. 2 .
- DE QuAdROS, R.; ROBLES, S.; LUCIANE, F.; COSTA, I.; PAMPLONA J. (1997) Apertura comercial y cambio estructural en la industria automotriz brasileña. Revista CEPAL, n. 63, p. 115-127.

- Diario Oficial de la Federación (DOF).(2007) Acuerdo por el que se da conocer el Primer protocolo adicional al ACE No. 55 entre los Estados Unidos Mexicanos y los cuatro Estados Parte del Mercosur. 2007. Disponible en: http://www.dof.gob.mx/nota_detalle.php?codigo=499679 $3 \&$ fecha=20/08/2007. Consultado en junio de 2014.

(2012) Acuerdo por el que se establece el cupo y mecanismo de asignación de vehículos ligeros nuevos hacia Brasil, conforme al Apéndice II sobre el Comercio en el Sector Automotor entre Brasil y México del ACE 55. 26/03/12. Disponible en: http://www.dof.gob.mx/nota_detalle.php?codigo $=524080$ 4\&fecha=26/03/2012. Consultado en junio de 2014.

.(2012) Acuerdo por el que se establece el saldo y la asignación del cupo para el periodo comprendido del 19 de marzo de 2012 al 18 de marzo de 2013 y el cupo y los montos asignados para los periodos comprendidos entre el 19 de marzo de 2013 al 18 de marzo de 2014 y 19 de marzo de 2014 al 18 de marzo de 2015, para la exportación de vehículos ligeros nuevos hacia Brasil conforme al Apéndice II sobre el comercio en el sector automotor entre Brasil y México del ACE 55. 30/04/2012. Disponible en: http://www.dof.gob.mx/nota_detalle.php?codigo $=524777$ 7\&fecha=30/04/2012. Consultado en junio de 2014.

(2014) Aviso por el que se comunica la asignación del cupo para la exportación de vehículos ligeros nuevos hacia Brasil. 15/01/2014. Disponible en: http://dof.gob.mx/nota_detalle.php?codigo $=5329667 \&$ fec ha $=15 / 01 / 2014$. Consultado en junio de 2014.

- Diario Oficial de la Unión (DOU).(2012) Dispõe sobre a distribuição de quotas tarifárias de exportação ao México de que trata o Quarto Protocolo Adicional ao Apêndice II "Sobre o Comércio no Setor Automotivo entre o Brasil e o México do Acordo de Complementação Econômica no 55 Mercosul/México". 03/04/2012. Disponible en: http://www.desenvolvimento.gov.br/arquivos/dwnl_13334 80353.pdf. Consultado en junio de 2014

- Federal Reserve System (FED).(2012) Brazil spot Exchange rate, Reais/US\$. Disponible en: http://www.federalreserve.gov/._Consultado en junio de 2014.

- ferreira F., V.S., PASCOAL, E.T., DA SilVA, A.C., OliVARES, G.L. \& ROCHA, H. (2013) Inovar-Auto \& Alianças Estratégicas: um novo cenário de cooperação para montadoras e fornecedores de auto-peças. X SEGetSimpósio de Excelência em Gestão e Tecnología, v. 23.

- $\quad$ figueroA, D.E., KATZ, L.F., SCARLAN, M.A. y SICA, D.E. EI (2016) fututor del Sector Automotriz en Argentina y el Mercosur (2025), Informe Anexo №1. Análisis del Programa Inovar-Auto e Inovar-Peças de Brasil. Buenos Aires: MCTIP.

- GARCíA, M.; VARGAS, J. (2013) Impacto estratégico del proteccionismo implementado por Brasil y Argentina en el ámbito de la industria automotriz mexicana. Innovaciones de negocios, v. 10, n. 19, p. 65-84. 
- GEREFFI, G. (1994) Rethinking Development Theory: Insights from East Asia and Latin America. In Porter, A. and Kincaid, D. (eds.). Comparative National Development. New York. The University of North Carolina Press, 1994 . (1994) KORZENIEWICZ, M. Commodity Chains and Global Capitalism. Westport, CT: Praeger.

(2001) Las cadenas productivas como marco analítico para la globalización. Problemas del Desarrollo, v. 32, n. 125, p. 9-37.

- GUimarÃES, E. A., A. (1989) industria automovilística brasileira na década de 80 , Pesquisa e Planejamento Econômico, V. 19, n. 2, pp. 347-378.

- Industria Nacional de Autopartes (INA). (2009). El sector de autopartes en México: Importancia del sector. 2009. Disponible en: http://www.ina.org.mx/. Consultado en: enero de 2014.

- Instituto Nacional de Estadística y Geografía (INEGI). (2006) La industria automotriz en México, edición 2006. México: Instituto Nacional de Estadística y Geografía.

.(2009) Censos económicos, edición 2009. México: Instituto Nacional de Estadística y Geografía.

- _. (2011) La industria automotriz en México, edición 2011. México: Instituto Nacional de Estadística y Geografía.

- _. _. (2013) La industria automotriz en México, edición 2013. México: Instituto Nacional de Estadística y Geografía.

- _. (2016) Cuentas Nacionales. 2016. Disponible en: http://www.inegi.org.mx/sistemas/bie/. Consultado en febrero de 2016.

- Instituto de Investigación Económica Aplicada de Brasil (IPEA). (2012) Importações e exportações - setor: veículos automotores, reboques e carrocerias- (FOB). 2012. Disponible en: http://www.ipeadata.gov.br. Consultado en junio de 2014.

- MARTín, V.; GONZÁleZ, M.(2013) Modelos de industrialización en el sector automotriz. Brasil y México. XVIII Congreso Internacional de Contaduría, Administración e Informática. México, Distrito Federal. Disponible en: http://congreso.investiga.fca.unam.mx/docs/xviii/docs/9.1 7.pdf Consultado en julio de 2014

- Ministério do Desenvolvimiento, Indústria e Comércio Exterior (MDICE). (2014). Intercambio comercial brasileiro: países e blocos económicos: México. Disponible en: http://www.mdic.gov.br/sitio/interna/interna.php?area=5 \&menu=576_Consultado en julio de 2014.

- MORAles M. E.; SERRANO, F. I. (2012) El eslabón que se rompe: el conflicto automotriz entre Brasil y México. Economía Actual, Revista de Análisis de Coyuntura Económica, v. 5, n. 2, p. 34-37.

- Observatorio de Competitividad de las Cadenas de Valor de México (2009). Programa de las Naciones Unidas para el Desarrollo en México (OCAV-PNUD). Análisis comparativo de la Industria Automotriz: resumen ejecutivo. México. PNUD.

- POZAS, M.A.(2001) “Globalización, industria y organización del Trabajo. Reflexiones para la construcción de un marco teórico", Estudios Sociológicos, vol. XIX, núm. 1, enero-abril, El Colegio de México, Distrito Federal, pp. 185-207.

- ROTTA, I. S., \& BUENO, F. (2000) Análise setorial da indústria automobilística: principais tendências. ENEGEP (Encontro Nacional de Engenharia de Produção), 20.

- ROSAS, M. (2008) México y Brasil: ¿Buenos enemigos o amigos mortales? Mosaico, v. 1, n. 1, p. 87-105, 2008.

- Secretaría de Economía (SE) (2016). IED trimestral por sector. Disponible en http://www.gob.mx/se/acciones-yprogramas/competitividad-y-normatividad-inversionextranjera-directa. Consultado en abril de 2016 (2012) Comunicados de prensa No. 040/12 y 083/12. Disponible en: www.economia.gob. $\mathrm{mx} /$. Consultado en febrero de 2013.

(2013) Estadísticas de IED. Disponible en: http://www.economia.gob.mx/comunidadnegocios/competitividad-normatividad/inversionextranjera-directa. Consultado en junio de 2014.

(2014) Balanza Comercial de México con Brasil. Disponible en: http://www.economia-snci.gob.mx/. Consultado en junio de 2014.

(2016) Estadísticas IED. Disponible en: http://www.economia.gob.mx/comunidadnegocios/competitividad-normatividad/inversionextranjera-directa. Consultado en febrero de 2016.

- SIQUeIROS, J. (2007) Régimen de solución de controversias en el acuerdo de complementación económica celebrado entre México y Brasil. Boletín Mexicano de Derecho

\section{Sobre os autores}

- Yolanda Carbajal-Suárez é Doctora en Economía por la Universidad Nacional Autónoma de México. Miembro del Sistema Nacional de Investigadores, Nivel 1 (Conacyt-México). Investigadora del Centro de Investigación en Ciencias Económicas, Facultad de Economía.E-mail: ycarbajals@uaemex.mx

- María Esther Morales-Fajardo é PhD in Social Sciences specialized in International Relations by the Metropolitan Autonomous University, Campus Xochimilco. She is a level 1 member of the Researchers National System (Conacyt-Mexico).E-mail:moralesf@correo.crim.unam.mx 


\section{O setor automotivo no México e no Brasil: Uma análise desde a perspectiva comercial}

Yolanda Carbajal-Suárez e María Esther Morales-Fajardo

Facultad de Economía, Universidad Autónoma del Estado de México, Ciudad de México, México

\begin{tabular}{l}
\hline DETALHES DO ARTIGO \\
\hline Histórico do artigo: \\
Recebido em 15 de março de 2016 \\
Aceito em 27 de setembro de 2016 \\
Disponível online em 31 de dezembro de 2016 \\
Sistema de Revisão "Double Blind Review" \\
Editor científico: \\
llan Avrichir
\end{tabular}

Palavras-chaves:

Setor automotivo; México; Brasil; ACE 55;

Comércio Internacional

\begin{abstract}
RESUMO
O desempenho e as características do setor automotivo no México e no Brasil são analisados, com destaque para os diferentes caminhos percorridos pelas respectivas indústrias e o comércio bilateral. A análise determinou que o Brasil tem dado prioridade ao fortalecimento do seu mercado doméstico, enquanto o México tem claramente dado prioridade ao mercado de exportação. No nível bilateral, a importância do intercâmbio comercial encontra-se no sector industrial, particularmente no sector automotriz; no entanto, essa relação foi diminuída como resultado da disputa que ocorreu no âmbito do Acordo de Complementação Econômica (ACE) 55.
\end{abstract}

(C) 2016 Internext | ESPM. Todos os direitos reservados!

Para citar este artigo:

Carbajal-Suárez, Y. \& Morales-Fajardo, M. E. (2016). El sector automotriz en méxico y Brasil: Un análisis desde la perspectiva comercial. Internext - Revista Eletrônica de Negócios Internacionais, 11 (3), 4-21. DOi: 10.18568/1980-4865.1134-21

Para acessar este artigo: $h t t p: / / d x . d o i . o r g / 10.18568 / 1980-4865.1134-21$ 